\title{
Prevalence of Masked and White-Coat Hypertension in Pre-Hypertensive and Stage 1 Hypertensive patients with the use of TeleMRPA
}

\author{
Weimar Kunz Sebba Barroso, ${ }^{1,2}$ Audes Diógenes Magalhães Feitosa, ${ }^{3 \oplus}$ Eduardo Costa Duarte Barbosa, ${ }^{4}$ Roberto \\ Dischinger Miranda, ${ }^{5}$ Andréa Araújo Brandão, ${ }^{6}$ Priscila Valverde Oliveira Vitorino, ${ }^{7}$ Lúcio Paulo de Souza Ribeiro, ${ }^{8}$ \\ Marco Mota Gomes ${ }^{9}$ \\ Universidade Federal de Goiás - Programa de Pós-Graduação em Ciências da Saúde, ${ }^{1}$ Goiânia, Goiás - Brazil \\ Universidade Federal de Goiás - Liga de Hipertensão Arterial, ${ }^{2}$ Goiânia, Goiás - Brazil \\ Laboratório de Imunopatologia Keizo Asami - Universidade Federal de Pernambuco, ${ }^{3}$ Recife, PE - Brazil \\ Instituto de Cardiologia - Laboratório de Investigação Clínica (LIC), ${ }^{4}$ Porto Alegre, RS - Brazil \\ Escola Paulista de Medicina - Universidade Federal de São Paulo - Cardiogeriatria, ${ }^{5}$ São Paulo, SP - Brazil \\ Universidade do Estado do Rio de Janeiro - Cardiologia, ${ }^{6}$ Rio de Janeiro, RJ - Brazil \\ Escola de Ciências Sociais e da Saúde - Pontifícia Universidade Católica de Goiás - Ciências Sociais, ${ }^{7}$ Goiânia, GO - Brazil \\ Universidade Federal de Pernambuco - Centro de Informática, ${ }^{8}$ Recife, PE - Brazil \\ Centro Universitário CESMAC - Hospital do Coração, ${ }^{9}$ Maceió, AL - Brazil
}

\section{Abstract}

Background: The diagnosis of arterial hypertension based on measurements of blood pressure in the office has low accuracy.

Objective: To evaluate the prevalence of masked hypertension (MH) and white-coat hypertension through home blood pressure monitoring (HBPM) in pre-hypertensive and stage 1 hypertensive patients.

Method: Retrospective study, of which sample consisted of individuals with $B P \geq 120 / 80 \mathrm{mmHg}$ and $<160 / 100 \mathrm{mmHg}$ at the medical office without the use of antihypertensive medication and who underwent exams on the HBPM platform by telemedicine (TeleMRPA) between May 2017 and September 2018. The four-day MRPA protocol was used, with 24 measurements, using automated, validated, calibrated equipment with a memory function.

Results: The sample consisted of 1,273 participants, of which $739(58.1 \%)$ were women. The mean age was $52.4 \pm 14.9$ years, mean body mass index (BMI) $28.4 \pm 5.1 \mathrm{~kg} / \mathrm{m}^{2}$. The casual BP was higher than the HBPM in $7.6 \mathrm{mmHg}$ for systolic blood pressure (SBP) and $5.2 \mathrm{mmHg}$ for diastolic blood pressure (DBP), both with statistical significance $(\mathrm{p}<0.001)$. There were 558 (43.8\%) normotensive individuals; 291 (22.9\%) with sustained hypertension; 145 (11.4\%) with MH and 279 (21.9\%) with white-coat hypertension (WCH), with a diagnostic error by casual BP in the total sample in $424(33.3 \%)$ patients. In stage 1 hypertensive individuals, the prevalence of $\mathrm{WCH}$ was $48.9 \%$; in prehypertensive patients, the prevalence of $\mathrm{MH}$ was $20.6 \%$.

Conclusion: $\mathrm{MH}$ and $\mathrm{WCH}$ have a high prevalence rate in the adult population; however, in prehypertensive or stage 1 hypertensive patients, the prevalence is higher. Out-of-office BP measurements in these subgroups should be performed whenever possible to prevent misdiagnosis. (Arq Bras Cardiol. 2019; 113(5):970-975)

Keywords: Hypertension/diagnosis; Masked Hypertension; White Coat Hypertensin; Hypertension SelfMonitoring; Telemedicine.

\section{Introduction}

The prevalence of arterial hypertension $(\mathrm{AH})$ in the Brazilian adult population is high and varies according to the studied population and the method of assessment (31\% to $35.8 \%)^{1}$ For this reason, the accurate diagnosis of the several scenarios related to blood pressure (BP) behavior is crucial for adequate

Mailing Address: Weimar Kunz Sebba Barroso Souza •

Universidade Federal de Goiás - Programa de Pós-Graduação em Ciências da Saúde - Avenida Universitária Hospital das Clínicas. Postal Code 74605-020,

Goiânia, GO - Brazil

E-mail: sebbabarroso@gmail.com,wsebba@uol.com.br

Manuscript received November 23, 2018, revised manuscript February 27, 2019, accepted April 05, 2019

DOI: 10.5935/abc.20190147 stratification of cardiovascular risk, as well as for the definition of the best treatment strategies. ${ }^{1,2}$

In this context, considerations should be given to the possibility of normotension, masked hypertension $(\mathrm{MH})$, white-coat hypertension ( $\mathrm{WCH}$ ), and sustained $\mathrm{AH} .^{3}$ $\mathrm{MH}$ is defined by the presence of normal BP in the office but high measurements outside of it; the $\mathrm{WCH}$ is defined by high values of BP in the office and normal values in the home measurements. It is noteworthy that $\mathrm{MH}, \mathrm{WCH}$ and $\mathrm{AH}$ are highly prevalent and are related to an increase in cardiovascular morbidity and mortality. ${ }^{4}$ Therefore, they should be investigated and diagnosed, and for this purpose, it is essential to use methods capable of monitoring BP outside the doctor's office environment. 5,6

Ambulatory (ABPM) or home (HBPM) BP monitoring can be used for home BP measurement, with the latter offering 
the possibility of providing the necessary information for the appropriate diagnosis with greater comfort and better cost-benefit ratio. ${ }^{7}$

Also, in relation to HBPM, the inclusion of the habitual BP measurements into the patient's routine has shown an increase in compliance with drug treatment. This benefit seems to be even greater when using telemedicine platforms. ${ }^{8,9}$

An adequate identification of $\mathrm{MH}$ and $\mathrm{WCH}$ is so important that the main guidelines of $\mathrm{AH}$ recommend the use of $\mathrm{ABPM}$ or HBPM in the diagnostic investigation whenever possible, emphasizing their use at the initial BP alterations. ${ }^{1,2,3,7}$

The present study is the first national study to evaluate the prevalence of $\mathrm{MH}$ and white coat hypertension through the HBPM in prehypertensive and stage 1 hypertensive patients.

\section{Method}

This study was submitted and approved by the Human Research Ethics Committee of Hospital das Clínicas da Universidade Federal de Goiás under CAEE number 99691018.7.0000.5078.

This is a retrospective study that evaluated the data of all patients who underwent exams on the TeleMRPA platform (www. telemrpa.com) from May 2017 to September 2018. Of the total, those who underwent the examination for diagnostic purposes and were not using antihypertensive drugs were selected.

Inclusion criteria were age older than 18 years; individuals assessed on the TeleMRPA platform, without the use of antihypertensive drugs and who had, by the casual measure (mean of two measurements) performed at the clinic on the first day of the protocol, SBP and DBP that met the criteria for the diagnosis of prehypertension $(\mathrm{PH})-\mathrm{SBP} \geq 120 \mathrm{mmHg}$ and/or $\mathrm{DBP} \geq 80 \mathrm{mmHg}$ and $\mathrm{SBP}<140 \mathrm{mmHg}$ and $\mathrm{DBP}<90 \mathrm{mmHg}$; or stage $1 \mathrm{AH}-\mathrm{SBP} \geq 140 \mathrm{mmHg}$ and/or DBP $\geq 90 \mathrm{mmHg}$ and SBP $<160 \mathrm{mmHg}$ and DBP $<100 \mathrm{mmHg}$, according to the Brazilian Guideline of Arterial Hypertension (DBHA, Diretriz Brasileira de Hipertensão Arterial). ${ }^{1}$

The TeleMRPA platform was developed as a telemedicine monitoring tool, with characteristics that allow the analysis and filtering of the database according to the scientific questions to be investigated. There was a concern to develop and improve the mathematical algorithm aiming to allow the high quality of the analyzable data, either for the interpretation of the exam or for the development of research projects. In this context, the database protects the identification data of the patient and clinics or health units. Prior to the inclusion of data into the platform, the co-investigators were trained regarding the scientific evidence and methodology of the HBPM, as well as for the use of Omron automatic devices for BP measurements.

The protocol used to obtain home measurements follows the recommendation of the Brazilian guidelines for $\mathrm{HBPM}^{7}$ which advises two measures to be carried out on the first day at the office or clinic (these measures are not used for the analysis of the mean home measurements) and six measurements a day on four consecutive days (three in the morning and three in the evening), with a total of 24 measures to calculate the mean. This mean value is considered normal when lower than 135/85 mmHg (Table 1). ${ }^{1,2,7,8}$

It is recommended, on the first day, when the patient receives the device at the health unit, that the patient be taught the correct handling of the BP measuring device, as well as the technique for adequate and reliable measurement. This recommendation follows the DBHA guidelines. ${ }^{1}$ Subsequently, the patient (or caregiver/companion) is instructed to measure the BP twice a day, following the abovementioned protocol.

Patient data, as well as BP values, were included into the TeleMRPA platform and analyzed for the following variables:

Socio-demographic data: gender, age, sample distribution and $\mathrm{BP}$ behavior by geographic regions;

Anthropometric data: BMI using the Quetelet formula $\left(\mathrm{BMI}=\right.$ weight in $\mathrm{kg} /$ height in meters $\left.^{2}\right)$.

Blood pressure: mean BP at the clinic (first day), mean of home BP measures (second to fifth days) and mean BP in morning and evening, mean pulse pressure and BP variability.

\section{Database and statistical analysis}

The database was created using the Excel ${ }^{\circledR}$ (Microsoft) software with data imported from the TeleMRPA platform; the numerical codes were typed by three researchers with subsequent cross-checking to identify and correct typing errors.

Continuous variables were presented as mean and standard deviation and categorical variables as absolute and relative frequencies. The Kolmogorov-Smirnov test was used to verify the distribution of the continuous variables. The paired $t$-test was used to compare BP measurements between the casual measurements and HBPM. To compare the frequencies of masked $\mathrm{AH}$ between stage 1 and stage 2 prehypertensive patients, the chi-square test was used, which was also used to compare the diagnoses of prehypertension and stage 1 hypertension between the casual BP measure and the HBPM. The significance level was set at $p<0.05$. The Stata ${ }^{\circledR}$ software, version 14.0 was used for the analysis.

\section{Results}

The initial sample consisted of 4,350 individuals who underwent HBPM from May 2017 to September 2018 in nine Brazilian states. Of these, 1,273 participants with a clinical diagnosis of prehypertension or stage $1 \mathrm{AH}$ and without use of medications (Figure 1) were selected, of which $853(67.0 \%)$ were from the Northeast region, 43 (3.4\%) from the North region, 10 (0.8\%) from the Midwest region, 307 (24.1\%) from the Southeast region and $60(4.7 \%)$ from the South region. Mean age was $52.4 \pm 14.9$ years and the mean BMI was $28.4 \pm 5.1 \mathrm{~kg} / \mathrm{m}^{2}$. As for gender, 739 (58.1\%) were women.

The mean values of casual BP were $133.2 \pm 11 \mathrm{mmHg}$ and $84.1 \pm 8 \mathrm{mmHg}$, and for HBPM, the mean values were $125.5 \pm 11.7 \mathrm{mmHg}$ and $78.9 \pm 8 \mathrm{mmHg}$ for SBP and DBP, respectively. The mean number of valid measures was 22.96 .

When comparing the means of the casual BP with the HBPM, higher values were found for casual BP in $7.6 \mathrm{mmHg}$ for SBP and $5.2 \mathrm{mmHg}$ for DBP, both with statistical significance $(p<0.001)$ (Figure 2$)$.

Considering the casual BP measurement, 703 (55.2\%) participants were classified as prehypertensive and 570 (44.8\%) as stage 1 hypertensive. When we considered the measures of the HBPM for the diagnosis, in the total sample, 558 (43.8\%) were normotensive; 291 (22.9\%) had sustained hypertension; 145 (11.4\%) had $\mathrm{MH}$; and 279 (21.9\%) had $\mathrm{WCH}$; that 


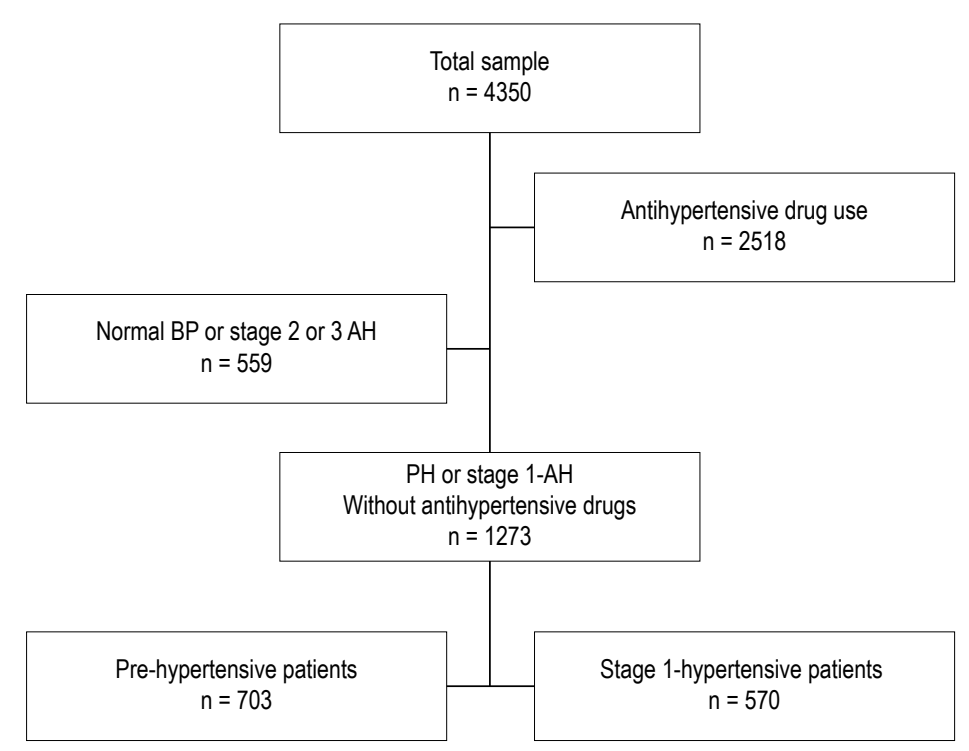

Figure 1 - Flowchart for the selection of individuals for the analysis. PH: pre-hypertension, AH: arterial hypertension.

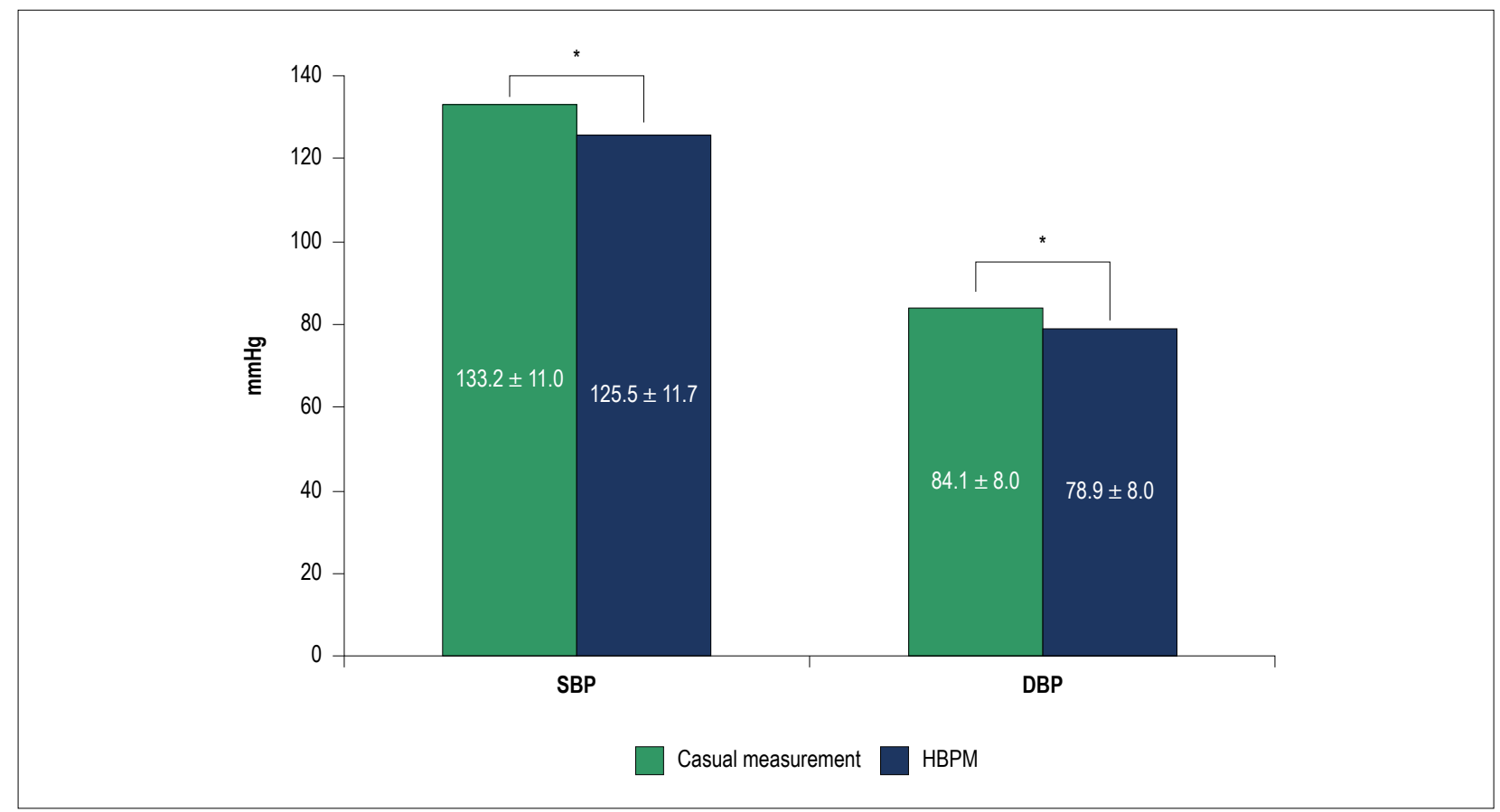

Figure 2 - Comparison of systolic and diastolic blood pressure measurements between casual methods and the home blood pressure measurement, $n=1273$. Paired $t$-test * $(p<0.001)$. SBP: systolic blood pressure; DBP: diastolic blood pressure; HBPM: home blood pressure monitoring.

is, in this population, $33.3 \%$ of the diagnoses by casual measurement were wrong.

When analyzing only the prehypertensive group, there were 145 individuals (20.6\%) who actually had masked hypertension, and if we separate those individuals with $\mathrm{SBP} \geq 130 \mathrm{mmHg}$ and $<140 \mathrm{mmHg}$, and/or $\mathrm{DBP} \geq 85 \mathrm{mmHg}$ and $<90 \mathrm{mmHg}(\mathrm{n}=364)$, the prevalence of $\mathrm{MH}$ increases to $27.8 \%$ (Table 2 ).
In the stage 1 hypertensive group, 279 individuals (48.9\%) with $\mathrm{WCH}$ were identified (Figure 3).

\section{Discussion}

The present study confirmed that the BP measurements obtained through HBPM is very useful in the diagnosis of $\mathrm{AH}$ phenotypes and allowed the reclassification of $33.3 \%$ of the assessed individuals, thus adding important information to the 
Table 1 - HBPM protocols according to the Brazilian guidelines for HBPM ( $\square \square \square / \square \square$ : blood pressure measurement). ${ }^{7}$

\begin{tabular}{|c|c|c|c|c|c|}
\hline $1^{\text {st }}$ day Medical office/clinic & HBPM & $2^{\text {nd }}$ day Home & $3^{\text {rd day Home }}$ & $4^{\text {th }}$ day Home & $5^{\text {th }}$ day Home \\
\hline \multirow{6}{*}{$\begin{array}{l}\text { Any time } \\
\square \square \square / \square \square \\
\square \square \square / \square \square\end{array}$} & \multirow{3}{*}{$\begin{array}{c}\text { Morning } \\
\text { Before breakfast }\end{array}$} & 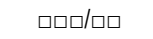 & 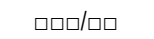 & 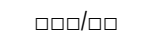 & 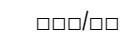 \\
\hline & & 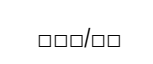 & 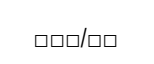 & 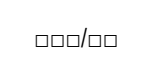 & $\square \square \square / \square \square$ \\
\hline & & 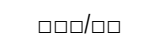 & 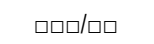 & $\square \square \square / \square \square$ & 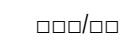 \\
\hline & \multirow{3}{*}{$\begin{array}{c}\text { Night } \\
\text { Before dinner or } \\
2 \text { hours later }\end{array}$} & 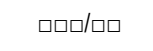 & 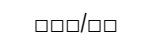 & 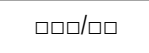 & प्व/प्र \\
\hline & & $\square \square \square / \square \square$ & 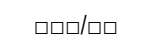 & $\square \square \square / \square \square$ & 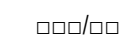 \\
\hline & & वपव/म० & वपव/प० & वपव/म० & वपव/प० \\
\hline
\end{tabular}

HBPM: home blood pressure monitoring.

Table 2 - Comparison of the prevalence of masked hypertension in pre-hypertensive patients with different blood pressure levels

\begin{tabular}{lcc}
\hline Blood pressure behavior & $\begin{array}{c}120 \geq \text { SBP }<130 \text { and } 80 \geq D B P<85 \text { mmHg } \\
\text { (casual measurement) } n(\%)\end{array}$ & $\begin{array}{c}130 \geq \text { SBP }<140 \text { e } 85 \geq \text { DBP }<90 \mathrm{mmHg} \\
\text { (casual measurement) } n(\%)\end{array}$ \\
\hline Normotension True hypertension & $295(87.0 \%)$ & $263(72.2 \%)$ \\
Masked Hypertension & $44(13.0 \%)$ & $101(27.8 \%)$ \\
Total & $339(48.2 \%)$ & $364(51.8 \%)$ \\
\hline
\end{tabular}

${ }^{*}$ Chi-square. SBP: systolic blood pressure; DBP: diastolic blood pressure.

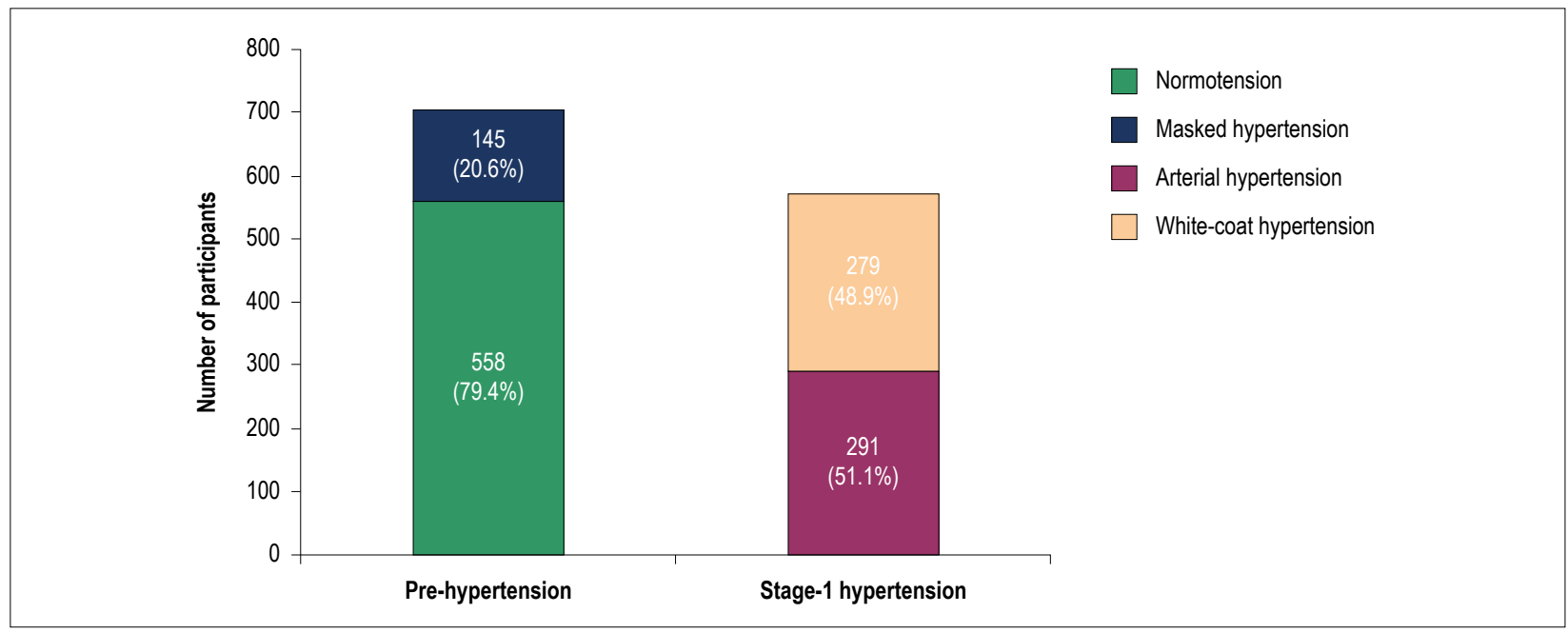

Figure 3 - Participants classified as prehypertensive and stage-1 hypertensive patients considering the casual measurement and reclassified according to the HBPM, $n=1,273$.

approach and follow-up of these individuals. We emphasize the significant number of individuals included in the study, from nine states of the five Brazilian geographic regions.

$\mathrm{AH}$ is a highly prevalent disease in the adult population; in a worldwide survey of 1,128,635 individuals, the prevalence was $34.9 \%$, most of them with stage 1 hypertension. It is also known that the prevalence of $\mathrm{PH}$ is at the same level, reinforcing the need for a correct diagnosis, so that the most appropriate conduct can be implemented..$^{10,11}$ It is also well established that BP monitoring methods outside the office, when compared to the casual measure, have a higher diagnostic accuracy and show a better prediction of cardiovascular risk. ${ }^{12,13}$

In the studied sample, when we compared the means of casual BP with HBPM, we found significantly lower means in HBPM, with statistically significant differences $(p<0.001)$ for both SBP and DBP.
Based on this scientific evidence, to avoid diagnostic error, the most recent $\mathrm{AH}$ guidelines have strongly recommended the use of ABPM or HBPM for diagnostic evaluation, especially in individuals with initial BP alterations. ${ }^{1,2,7}$

When only those individuals with diagnostic criteria for $\mathrm{PH}$ or stage $1 \mathrm{AH}$ were assessed, in which the chance of casual measures that induce misdiagnosis is higher, we found a prevalence of true normotension and hypertension of only $66.7 \%$, that is, in $33,3 \%$ of the cases, the diagnosis would have been wrong, if we considered only the casual measure. These data coincide with other publications that found similar error rates. ${ }^{14-16}$

The risk of $\mathrm{WCH}$ in stage 1 hypertensive patients is even more important, or $\mathrm{MH}$ in prehypertensive patients because, contrary to what was believed, both $\mathrm{WCH}$ and $\mathrm{MH}$ are associated with higher cardiovascular mortality and, in the specific case of $\mathrm{MH}$, this mortality is even higher than 
that of patients with sustained hypertension..$^{4,17}$ It is worth mentioning that this prevalence is high in adults, but it is also significant in adolescents. ${ }^{6}$

In the sample of the present study, among the prehypertensive patients $(n=703)$, we found a prevalence of $\mathrm{MH}$ of $20.6 \%$; this value is even higher when we analyze the highest BP strata in this group. In $\mathrm{PH}$ patients with SBP $\geq 130 \mathrm{mmHg}$ and/or DBP $\geq 85 \mathrm{mmHg}$, this prevalence is $27.8 \%$, significantly higher $(p<0.001)$ than $\mathrm{PH}$ patients with BP levels lower than 130/85 mmHg. Our findings are in agreement with the trend seen at the last guidelines and statements, ${ }^{1,2,5,18-21}$ which dedicate special attention to prehypertensive individuals, since some of these individuals will show a significant increase in cardiovascular outcomes. It is also justifiable recommending the American and European guidelines regarding the performance of $\mathrm{ABPM}$ or HBPM whenever possible when casual BP is $\geq 130 / 85 \mathrm{mmHg}$.,19

Finally, when we evaluated the individuals diagnosed as stage 1 hypertension ( $\mathrm{n}=570$ ), we found a prevalence of $\mathrm{WCH}$ of $48.9 \%$, which could result in misdiagnosis and use of inadequate therapeutic strategies in almost half of these individuals.

Most of this sample consisted of individuals from the Northeast region of the country $(67.7 \%)$; this may be considered a limitation; however, as the analysis refers to $\mathrm{AH}$ phenotypes, it seems to us that the geographic region distribution would have little or no effect on the results.

The Telemedicine MRPA (TeleMRPA) platform is an extremely useful, low-cost, easy-to-perform and wide-ranging modality, allowing a systematic evaluation of home-based BP measures, in accordance with the DBHA recommendations. In addition to the individual evaluation in clinical practice, the accumulation of information on this platform represents an important database for analyses on the diagnosis and treatment of $\mathrm{AH}$ in several regions of Brazil, both in public and private institutions.

\section{Conclusion}

The casual BP measurement is a method used for $\mathrm{AH}$ screening, but it is necessary to take into account that home measurements are more accurate for the diagnosis.

We found high prevalence rates of $\mathrm{MH}$ and white-coat hypertension in individuals diagnosed with prehypertension or stage- 1 hypertension.

The TeleMRPA platform allowed the reclassification of $33.3 \%$ of the assessed individuals.

\section{National Co-Investigators}

Adriana C. Oliveira (Clínica Vittá, Goiânia), Adriana Serpa (Clínica SAVE, Recife), Andresson W. Andrade (Icordis, Caruaru), Ana C. Arantes (Universidade Federal de Goiás, Goiânia), Annelise M. G. Paiva (Centro Universitário CESMAC, Alagoas), Antônio A. M. A. Braga (Clínica Antônio Almeida, Recife), Carlos A. Machado (Núcleo de Apoio à Estratégia Saúde da Família. Secretaria Municipal de Saúde de Campos do Jordão), Cláudia F. Gonçalves (Universidade Federal de Goiás, Goiânia), Cleuriberto V. Pereira (Cardiocity, Guarulhos), Danielle B. L. Melo (Cardiologia IMIP, Recife), Ederaldo B. Leite (Cárddio - Hospital Anchieta, Taguatinga), Elder G. A. Cruz (Clínica Santa Louise, Salgueiro), Fábio Argenta (Clínica Mediodonto, Lucas do Rio Verde), Fábio S. Silveira (Clinica do Coração, Sergipe), Fernando M. F. França (Clínica Cardiovasf, Petrolina), Gustavo A. C. S. Barros (MCor, Recife), Jadil F. F. Júnior (Clínica CardioService, Porto Velho), João A. C. Berigó (Universidade Federal de Goiás, Goiânia), Josafá O. Costa (Clínica Vitta, Igarassu), Luiz H. Thompson (Prev-Saúde, Recife), Luiz Kencis Jr (Centro de Medicina Avançada Dr Luiz Kencis, São Paulo), Marcelo De' Carli (Clínica Ipado, Petrolina), Marcelo J. Oliveira (Cardiográficos - Diagnóstico em Cardiologia, Ribeirão Preto), Marco A. M. Alves (Escada Clinical Center, Escada), Marcos A. P.Meira Junior (Clincar, João Pessoa), Mariana B. C. Sepulvida (Universidade Federal de São Paulo, São Paulo), Nelson Dinamarco (Laboratório de Hipertensão Arterial-UESC, Salvador), Renné G. Busnello (Clinicordis - Diagnóstico em Cardiologia, Porto Alegre), Stephan Barisic Junior (Clínica do Coração, Mossoró), Valdir L. Schwerz (Clínica Fares, São Paulo).

\section{Author contributions}

Conception and design of the research and Acquisition of data: Souza WKSB, Feitosa ADM, Barbosa ECD; Analysis and interpretation of the data: Souza WKSB, Feitosa ADM, Barbosa ECD, Miranda RD, Brandão AA, Gomes MM; Statistical analysis:Vitorino PVO; Obtaining financing: Souza WKSB; Writing of the manuscript: Souza WKSB, Feitosa ADM, Barbosa ECD, Brandão AA; Critical revision of the manuscript for intellectual content: Souza WKSB, Feitosa ADM, Barbosa ECD, Miranda RD, Brandão AA, Vitorino PVO, Gomes MM; Platform development and support (www.telemrpa.com): Ribeiro LPS.

\section{Potential Conflict of Interest}

No potential conflict of interest relevant to this article was reported.

\section{Sources of Funding}

This study was funded by Indústria Farmacêutica E.M.S.

\section{Study Association}

This study is not associated with any thesis or dissertation work.

\section{Ethics approval and consent to participate}

This study was approved by the Human Research Ethics Committee of Hospital das Clínicas da Universidade Federal de Goiás under the protocol number CAEE 99691018.7.0000.5078. All the procedures in this study were in accordance with the 1975 Helsinki Declaration, updated in 2013. 


\section{References}

1. Malachias MVB, Souza WKSB, Plavnik FL, Rodrigues CIS, Brandão AA, Neves MFT, et al.,Sociedade Brasileira de Cardiologia. 7a Diretriz Brasileira de Hipertensão Arterial. Arq Bras Cardiol. 2016;107(3):1-103.

2. Williams B, Mancia G, Spiering W Agabiti Rosei E, Azizi M, Burnier M, et al. $2018 \mathrm{ESC} / \mathrm{ESH}$ Guidelines for the management of arterial hypertension. Eur Heart J. 2018;39(33):3021-104.

3. Parati G, Stergiou G, O’Brien E Asmar R, Beilin L, Bilo G, et al. European Society of Hypertension practice guidelines for ambulatory blood pressure monitoring. J Hypertens. 2014;32(7):1359-66.

4. Banegas JR, Ruilope LM, de la Sierra A Vinyoles E, Gorostidi M, de la Cruz J, et al. Relationship between clinic and ambulatory blood-pressure measurements and mortality. N Engl J Med. 2018;378(16):1509-20.

5. Alessi A, Brandao AA, Paiva AMGNogueira AR, Feitosa A, Gonzaga CC, et al. I Brazilian position paper on prehypertension, white coat hypertension and masked hypertension: diagnosis and management.. Arq Bras Cardiol. 2014;102(2):110-9.

6. Jardim TV, Carneiro CS, Morais PRoriz V, Mendonça KL, Nascente FM, . et al White-coat, masked and sustained hypertension detected by home blood pressure monitoring in adolescents: prevalence and associated factors. Blood Press. 2018;27(3):151-7

7. Nobre F, Mion Júnior D, Gomes MAM, Barbosa ECD, Rodrigues CIS, Neves MFT, et al. 6 as Diretrizes de monitorização ambulatorial da pressão arterial e 4 as Diretrizes de monitorização residencial da pressão arterial. Arq Bras Cardiol. 2018;110(5):1-29.

8. Feitosa AD, Gomes MA, Mion Júnior D. How many days, which period of the day and how many measurements per day are recommended in home blood pressure monitoring? Arq Bras Cardiol. 2005;85(3):210-1

9. McManus RJ, Mant J, Franssen M,Nickless A, SchwartzC, Hodgkusson J et al. Efficacy of self-monitored blood pressure, with or without telemonitoring, for titration of antihypertensive medication (TASMINH4): an unmasked randomised controlled trial. Lancet. 2018;391(10124):949-59.

10. Souza WK, Jardim PC, Brito LP, Araújo FA, Souza AL. Self measurement of blood pressure for control of blood pressure levels and adherence to treatment. Arq Bras Cardiol. 2012;98(2):167-74

11. Beaney T, Schutte AE, Tomaszewski M, Ariti C, Burrell LM, Castillo RR, et al. May Measurement Month 2017: an analysis of blood pressure screening results worldwide. Lancet Glob Health. 2018;6(7):e736-e43.
12. Morales Salinas A, Coca A, Olsen MH, Sanchez RA, Sebba-Barroso WK, Kones $\mathrm{R}$, et al. Clinical perspective on antihypertensive drug treatment in adults with grade 1 hypertension and low-to-moderate cardiovascular risk: an international expert consultation. Curr Probl Cardiol. 2017;42(7):198-225.

13. Breaux-Shropshire TL, Judd E, Vucovich LA, Shropshire TS, Singh S. Does home blood pressure monitoring improve patient outcomes? A systematic review comparing home and ambulatory blood pressure monitoring on blood pressure control and patient outcomes. Integr Blood Press Control. 2015 Jul 3;8:43-9.

14. Souza WKSB, Jardim PCBV, Porto LB, Araújo FA, Sousa ALL, Salgado CM Comparison and correlation between self-measured blood pressure, casual blood pressure measurement and ambulatory blood pressure monitoring. Arq Bras Cardiol. 2011;97(2):148-55

15. Omboni S, Aristizabal D, De la Sierra A, Dolan E, Head G, Kahan T, et al Hypertension types defined by clinic and ambulatory blood pressure in 14143 patients referred to hypertension clinics worldwide. Data from the ARTEMIS study. J Hypertens. 2016;34(11):2187-98.

16. O'Brien E. Ambulatory blood pressure measurement: the case fo implementation in primary care. Hypertension. 2008;51(6):1435-41.

17. Staessen JA, Thijs L, Ohkubo T, Kikuya M, Richart T, Boggia J, et al. Thirty years of research on diagnostic and therapeutic thresholds for the self-measured blood pressure at home. Blood Press Monit. 2008;13(6):352-65.

18. Fagard $\mathrm{RH}, \mathrm{Celis} \mathrm{H}$. Prognostic significance of various characteristics of outof-the-office blood pressure. J Hypertens. 2004;22(9):1663-6.

19. Whelton PK, Carey RM, Aronow WS, Casey DE Jr, Collins KJ, Dennison Himmelfarb C, et al. 2017 ACC/AHA/AAPA/ABC/ACPM/AGS/APhA/ ASH/ASPC/NMA/PCNA guideline for the prevention, detection, evaluation, and management of high blood pressure in adults: executive summary: a report of the American College of Cardiology/American Heart Association Task Force on Clinical Practice Guidelines. Circulation. 2018;138(17):e426-e83

20. Feitosa ADM, Mota-Gomes MA, Miranda RD, Barroso WS, Barbosa ECD Pedrosa RP, et al. Impact of 2017 ACC/AHA hypertension guidelines on the prevalence of white-coat and masked hypertension: a home blood pressure monitoring study. J Clin Hypertens (Greenwich). 2018;20(12):1745-7.

21. Stergiou GS, Kario K, Kollias A, McManus RJ, Ohkubo T, Parati G, et al. Home blood pressure monitoring in the 21st century. J Clin Hypertens. (Greenwich). 2018;20(7):1116-21. 